\title{
Excretion of Haemophilus influenzae Type b Polysaccharide Antigen in Urine of Healthy Nasopharyngeal Carriers ${ }^{1}$
}

\author{
TRUDY V. MURPHY, JOE F. CLEMENTS, AND DAN M. GRANOFF
}

\begin{abstract}
Department of Pediatrics, University of Texas Southwestern Medical Center, Dallas, Texas 75235; the Division of Infectious Diseases, the Edward Mallinckrodt Department of Pediatrics, Washington University School of Medicine, and Children's Hospital, St. Louis, Missouri 63110
\end{abstract}

\begin{abstract}
We measured concentrations of Haemophilus influenzae type $\mathrm{b}$ (Hib) polysaccharide antigen by ELISA in urine samples from 81 healthy North American children with positive or negative throat cultures for $\mathbf{H i b}$, to investigate the possibility that asymptomatic carriers may have antigenuria. For comparison, we determined the concentrations of Hib polysaccharide antigen in urine samples from 56 patients with proven Haemophilus disease, including 13 children with lower respiratory infections who resided in developing countries. Among the healthy children, antigen was detected in the urine of seven of $19(37 \%)$ carriers of Hib compared with one of $62(2 \%)$ children with negative throat cultures $(p<0.001)$. Among the patients with invasive Haemophilus infections, $93 \%$ had antigen detected. Although there was overlap in the concentrations of antigen in the positive urines from the asymptomatic carriers and those of the ill patients, the concentrations of the ill patients were higher than those of the carriers. The respective geometric means of the positive patients were: American patients with meningitis, $42.5 \mathrm{ng} /$ $\mathrm{mL}$ (range 1.7-9800 $\mathrm{ng} / \mathrm{mL}$ ); American patients with infections not involving the CNS, $5.8 \mathrm{ng} / \mathrm{mL}$ (range: $1.0-96$ $\mathrm{ng} / \mathrm{mL}$ ); patients from developing countries with lower respiratory infections, $29.6 \mathrm{ng} / \mathrm{mL}$ (range: $0.9-5290$ ), and American asymptomatic carriers, $1.9 \mathrm{ng} / \mathrm{mL}$ (range: $0.6-$ $16.7 \mathrm{ng} / \mathrm{mL}$ ). Thus, antigenuria is present in a high proportion of healthy children with positive throat cultures for Hib, and the antigen concentrations of the carriers overlap those of ill patients. These results suggest that either mucosal colonization itself is sufficient to produce antigenuria, or asymptomatic carriers may be experiencing asymptomatic invasive Hib infection. (Pediatr Res 26: 491-495, 1989)
\end{abstract}

\section{Abbreviations}

Hib PS, Haemophilus influenzae type b polysaccharide LRI, lower respiratory infection

A, absorbance

Received April 5, 1989; accepted June 20, 1989

Correspondence and reprint requests Dan M. Granoff, MD., Washington University School of Medicine, 400 South Kingshighway Blvd., St. Louis, MO 63110 .

Supported by Grants R01 AI 21842 and AI 24332 from the National Institute of Allergy and Infectious Diseases, $\mathrm{NIH}$; a grant from the Fikes Foundation; and Contract AID-2429-8-312 from the Board on Science and Technology for International Development, National Research Council, U.S.A. by means of a grant from the U.S. Agency for International Development.

'Presented, in part, at the Annual Meeting of the Society for Pediatric Research, Washington, D.C., held May 4, 1989.
Protection against invasive Hib infection correlates with the presence of serum anticapsular antibody $(1,2)$. Antigens that stimulate production of anticapsular antibody come from a variety of sources (3-5). Important among these is asymptomatic nasopharyngeal colonization with Hib, which occurs in an estimated $38 \%$ of children before 5 y of age (5). Most children colonized with Hib (carriers) who are 2 y of age and older develop high concentrations of serum anticapsular antibody (6-9). The manner in which colonization results in increases in serum anticapsular antibody concentration is not known $(8,10)$ but, because the children are asymptomatic, it has been presumed that the immunization occurs primarily via the mucosal route. However, studies have not been done to determine whether asymptomatic carriers have evidence of antigenuria or invasive Hib infection, which, if present, would be sources of systemic immunization.

In our study, we used a highly sensitive and quantitative ELISA to measure concentrations of type b polysaccharide in the urines of healthy nasopharyngeal carriers of Hib. The concentrations of antigen in the urines of the carriers were compared to the antigen concentrations in urine samples from healthy children with negative throat cultures, and from patients with proven invasive Hib diseases treated in the United States or in developing countries.

\section{MATERIALS AND METHODS}

Healthy subjects. A signed consent for obtaining a throat culture and urine specimen was obtained from the parents of preschool children attending five day care centers in Dallas, TX where there had been recent cases of invasive Hib infection. Parents were asked to record the dates of the child's last fever, antibiotic use, and vaccination with Hib PS. Children who had fever, or who had received Hib vaccine or rifampin within the previous $30 \mathrm{~d}$ were excluded. At the first center studied, urine samples and throat cultures were obtained from children who had had positive throat cultures $1 \mathrm{wk}$ earlier. At the remaining four centers, there was no information available on prior culture status of the children and the specimens were obtained from all children whose parents consented. Asymptomatic siblings of two patients with invasive Hib infection had throat cultures and urine specimens obtained before beginning rifampin prophylaxis, and also were included in the study (one family in St. Louis and one in Dallas).

Ill patients. Two groups of patients with invasive Haemophilus disease, proven by isolation of Haemophilus influenzae from a normally sterile body fluid or tissue, were enrolled. The first group consisted of 43 patients hospitalized at Children's Medical Center or Parkland Memorial Hospital in Dallas, TX, or St. Louis Children's Hospital, MO. Isolates from all 43 were con- 
firmed as serotype $b$ by slide agglutination or counter current immunoelectrophoresis (11). The second group of patients consisted of 13 children with LRI and positive blood or pleural fluid cultures for $H$. influenzae who were enrolled in prospective studies of the etiology of acute lower respiratory infection in developing countries. These latter children resided in Argentina $(n=2)$, Colombia $(n=2)$, Guatemala $(n=1)$, Papua New Guinea $(n=7)$, or Uruguay $(n=1)$. Eight of the 13 isolates from these children were confirmed as serotype b in St. Louis. The remaining five isolates were not available for further study but four of the five were considered to be type $b$ by the local laboratory. The fifth isolate was considered to be nontypable by the local laboratory but the child is included because type $b$ polysaccharide was detected in the urine by ELISA.

Throat cultures. Throat cultures were obtained from the healthy control children by thoroughly swabbing both tonsils and the posterior pharynx. The swab was placed in Brain Heart Infusion broth supplemented with Levinthal base and bacitracin, modifying the method previously described (12). The broth was incubated overnight at $37^{\circ} \mathrm{C}$ in $5 \% \mathrm{CO}_{2}$ and, the next day, an aliquot of $0.001 \mathrm{~mL}$ of the broth culture was inoculated onto chocolate agar medium and incubated overnight in the same manner. Colonies with typical morphology on chocolate agar were isolated for identification and confirmation of $H$. influenzae as described (11). The presence of the type $b$ capsule was determined by precipitin halo formation on Levinthal agar containing $5 \%$ burro anti- $H$. influenzae type b antiserum (12) (Burro 132, serum generously provided by John Robbins, National Institutes of Health, Bethesda, MD).

Urine samples. Voided urine samples from the healthy children were collected by their parents or by day care personnel. The samples were refrigerated for up to $24 \mathrm{~h}$ before storing at -20 or $-70^{\circ} \mathrm{C}$. In the ill patients from Dallas and St. Louis, unused portions of urine samples that had been requested by the patients' physicians as part of the admission diagnostic evaluation were stored frozen at $-20^{\circ} \mathrm{C}$ and assayed for antigen in batch as described below. In the patients from developing countries, the urine samples were obtained within $24 \mathrm{~h}$ of obtaining the blood cultures, and were transported and stored frozen until being assayed in St. Louis. Before testing, all urine samples were centrifuged for $1 \mathrm{~min}$ in an Eppendorf microfuge (model 5412) to remove debris and cold precipitates. Urine samples from the asymptomatic children and ill patients were assayed without knowledge of the results of the throat cultures or the diagnosis, respectively.

Polysaccharide antigens. Capsular polysaccharides from Hib [strain Minn A, (13)], and Escherichia coli K100 [strain Easter (3)] were purified from supernatants of stationary phase broth cultures, as previously described (14). Protein $(<2 \%)$ and nucleic acid $(<1 \%)$ contents were determined as described (14). Preparations of purified polysaccharide of Streptococcus pneumoniae types $3,6,14,19$, and 23 were obtained from the American Type Tissue Collection (Rockville, MD).

Antisera. To "capture" the polysaccharide antigen, we used affinity-purified anticapsular antibody purified from Hib burro antiserum. (This burro antiserum was provided by Dr. Mary Glode, University of Colorado School of Medicine, Denver, CO). Affinity purified anticapsular antibody was prepared on a $\mathrm{Hib}$ PS-aminohexy-sepharose column as previously described (15), and was stored frozen in small portions at a concentration of $1500 \mu \mathrm{g} / \mathrm{mL}$ of antibody, as determined by a radioantigen binding assay (14). To detect the "captured" antigen, we used hyperimmune rabbit antisera as our second antibody. This antiserum was prepared at Washington University by immunization of a rabbit with repeated injections of $H$. influenzae b-diphtheria toxoid conjugate vaccine (Connaught Laboratories, Swiftwater, PA). Postimmunization sera were pooled and stored frozen in small portions. The anticapsular antibody concentration of the rabbit antiserum pool was approximately $700 \mu \mathrm{g} / \mathrm{mL}$.

ELISA. The technique used was modified after that described by Pepple et al. (16). The most important change was that we used affinity purified burro anticapsular antibody to capture Hib PS antigen, and used high-titer conjugate vaccine-induced rabbit antibody to detect complexed antigen, instead of using burro and rabbit antisera prepared against whole Hib bacterial cells as in the earlier study. Inasmuch as antisera to whole cells also contain antibodies to lipopolysaccharide and outer membrane proteins, this modification resulted in increased specificity of detection of capsular antigen.

In brief, 96-well Limbro E.I.A. microtitration plates (Flow Laboratories, Inc., McLean, VA) were sensitized with $100 \mu \mathrm{L}$ of affinity-purified burro anticapsular antibody, diluted to a concentration of $3 \mu \mathrm{g} / \mathrm{mL}$ of antibody in borate-buffered saline ( $\mathrm{pH}$ $8.20)$. After $4 \mathrm{~h}$ incubation at room temperature $\left(\sim 23^{\circ} \mathrm{C}\right)$, the plates were washed three times with PBS containing $0.05 \%$ Tween 20 (PBS-Tween, pH 7.40), and incubated for $1 \mathrm{~h}$ at room temperature with $100 \mu \mathrm{L}$ of PBS containing 1\% BSA (blocking step). After washing three times with PBS-Tween, $100 \mu \mathrm{L}$ of the urine samples was added to each well. The plates were incubated for $2 \mathrm{~h}$ at $37^{\circ} \mathrm{C}$ and then overnight at $4^{\circ} \mathrm{C}$. The next day, the plates were washed three times with washing buffer and incubated at $37^{\circ} \mathrm{C}$ for $2 \mathrm{~h}$ with the rabbit anti-Hib PS antiserum, diluted 1:500 in PBS-Tween. The plates were then washed three times and the presence of the rabbit IgG was detected by incubation for $2 \mathrm{~h}$ at $37^{\circ} \mathrm{C}$ with alkaline phosphatase conjugated goat antirabbit IgG [whole molecule, affinity-isolated antibodies, absorbed by the manufacturer to remove reactivity to human serum proteins (Sigma no. A-7539, Sigma Chemical Company, St. Louis, MO)], followed by washing three times and adding a solution of $p$-nitrophenol phosphate $(1 \mathrm{mg} / \mathrm{mL})$ in $10 \%$ diethanolamine buffer ( $\mathrm{pH} 9.8$ ). Absorbance at $405 \mathrm{~nm}$ was monitored after 15,30 , and 45 min incubation using a Titertek multiscan spectrophotometer (Flow Laboratories). Negative controls on each ELISA plate consisted of duplicate wells containing normal human urine alone, and normal human urine with $5 \mu \mathrm{g} / \mathrm{mL}$ of Hib PS added and subsequently developed with normal rabbit serum instead of the immune rabbit serum as the second antibody. Both of these controls gave $A$ values $<0.20$. Positive controls on each microtiter plate consisted of wells containing normal human urine to which Hib PS had been added to final concentrations of 5 and $1.2 \mathrm{ng} / \mathrm{mL}$. The A values of these positive wells corresponded closely to those of the standard titration curve performed on one of the microtiter plates (representative A values of 1.6 and 0.7 , respectively).

Figure 1 shows a typical titration curve of absorbance as a function of concentrations of different polysaccharides added to urine from a healthy adult. [Identical curves were obtained when the polysaccharides were added to PBS (data not shown)]. The data shown represent the actual A values, without subtraction of background absorbance measured in the normal urine without added antigen. For detection of Hib PS, the assay was linear for sample dilutions of Hib PS producing A values of 0.3 to 1.5 . Hib PS antigen concentrations $\geq 0.6 \mathrm{ng} / \mathrm{mL}$ gave absorbance values $>3$-fold above background and were considered positive. The urine from the healthy adult without added antigen, or the normal urine containing up to $10000 \mathrm{ng} / \mathrm{mL}$ of pneumococcal polysaccharide types $3,6,14,19$, or 23 gave background absorbance values of $<0.2$. However, cross-reactive $E$. coli $\mathrm{K} 100$ polysaccharide, containing a ribose $(1 \rightarrow 2)$ ribitol linkage instead of the ribose $(1 \rightarrow 1)$ ribitol linkage present in Hib PS, could be detected at concentrations of approximately 100 -fold higher than that giving a positive reaction with Hib PS (Fig. 1).

All urine samples from patients and healthy controls were initially assayed undiluted and positive results were confirmed in a second assay at which time a complete titration curve of the test sample was constructed by plotting absorbance as a function of reciprocal sample dilution, using a semilogarithmic scale. For urine samples with $>5.0 \mathrm{ng} / \mathrm{mL}$ of Hib PS, concentrations of antigen were calculated from the sample dilution yielding an $\mathrm{A}$ value of 0.7 (i.e. the 0.7 intercept). In all instances, the titration 


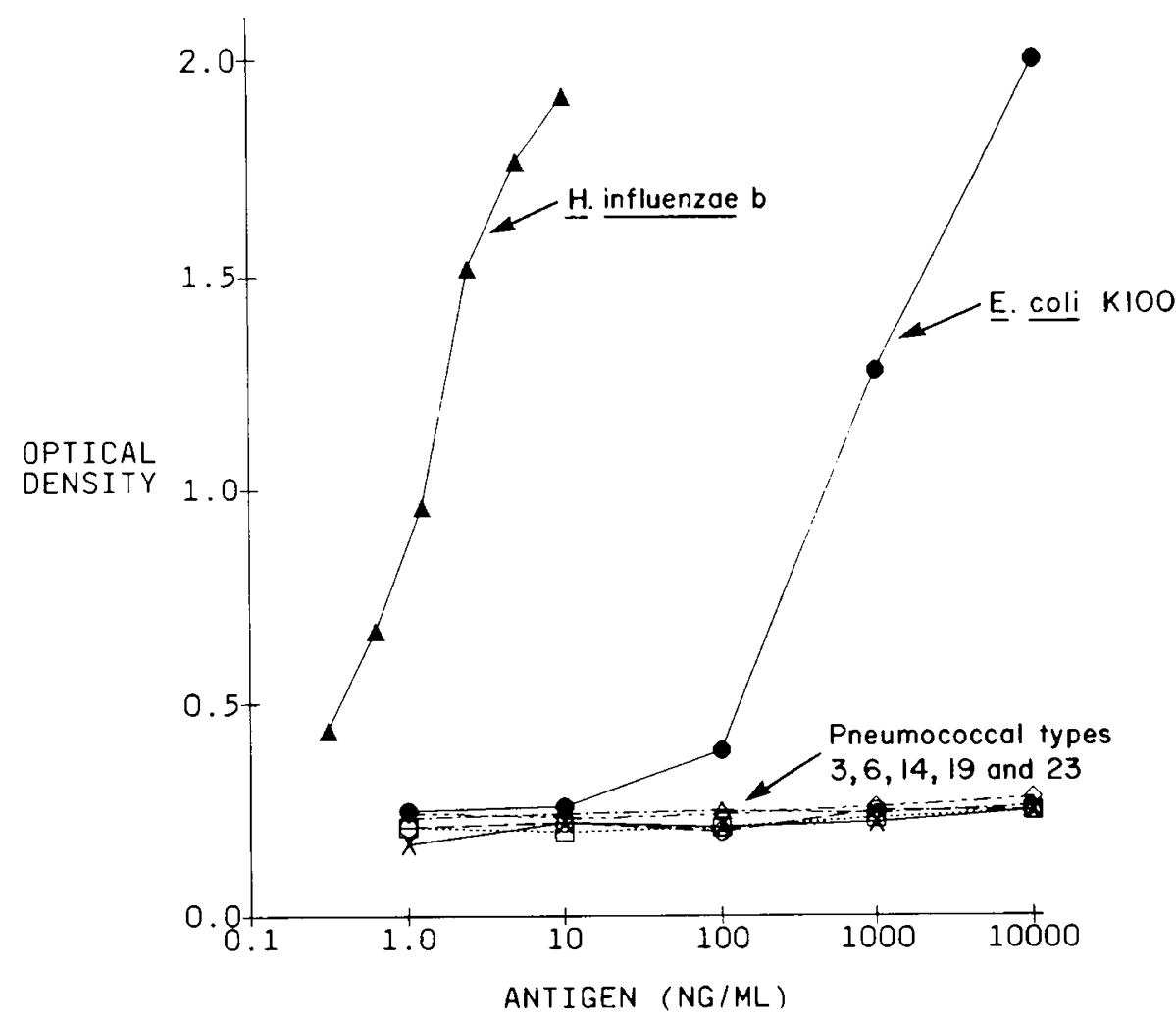

Fig. 1. Determination of absorbance as a function of the concentration of polysaccharides added to normal human urine (Haemophilus influenzae type b, E. coli K100, and S. pneumoniae serotypes 3, 6, 19, 14, and 23). Absorbance was measured after incubation for 30 min with substrate. The data shown are the actual absorbance values, without subtraction of background A present in the negative control urine. The curve obtained with normal urine without added polysaccharide was identical to those obtained with the $S$. pneumoniae serotypes.

curves of the test samples were parallel to that of the standard curve obtained with normal urine to which known concentrations of Hib PS had been added.

Comparison of ELISA with commercial agglutination tests. In two blinded comparisons performed on normal urine to which different concentrations of Hib PS had been added, antigen concentrations between 0.6 and $1.2 \mathrm{ng} / \mathrm{mL}$ gave strong positive reactions by ELISA $(A \geq 0.6)$ but gave negative or inconclusive results when tested with three commercial agglutination tests, each performed according to the manufacturers' directions (Directigen, BBL Microbiologic Systems, Cockeysville, MD; Wellcogen, Wellcome Diagnostics, Dartford, England; and Bactigen, Wampole Laboratories, Cranbury, NJ). With the Directigen and Wellcogen tests, the lowest concentration of Hib PS to give a definite positive result was $5.0 \mathrm{ng} / \mathrm{mL}$ of antigen, and with the Bactigen, $2.5 \mathrm{ng} / \mathrm{mL}$. The normal urine, to which antigen had not been added, gave negative results with the ELISA and with all three agglutination methods. Comparisons also were performed with dilutions of urine from a patient with Hib bacteremia: in this specimen, the ELISA was 4- to 6-fold more sensitive for antigen detection than any of the three commercial agglutination tests (data not shown).

Statistical methods. Log transformations were performed on the antigen concentrations of the urine samples, and the geometric means of the antigen concentrations of the carriers and the different patient groups were compared using a $t$ test. In this analysis, only patients with detectable urine antigen were included. Other statistical comparisons were performed using a $\chi^{2}$ test or Fisher exact test, when appropriate.

\section{RESULTS}

Figure 2 shows the Hib polysaccharide antigen concentrations in urine samples from individual patients with Haemophilus disease and asymptomatic control children. Overall, $93 \%$ of the ill patients had antigen detected in urine $(92 \%$ of the patients with LRI from developing countries, and 96 and $90 \%$, respectively, of the patients from the United States with meningitis or other forms of invasive Hib disease). Among patients with positive urines, the geometric mean of the antigen concentrations of the patients with LRI from developing countries was not significantly different from that of the patients with meningitis from the United States (29.6 versus $42.5 \mathrm{ng} / \mathrm{mL}$, respectively, $p>$ 0.40 ). However, both of these patient groups had significantly higher urine antigen concentrations than those of the United States patients with invasive forms of $\mathrm{Hib}$ disease not involving the central nervous system (geometric mean $=5.2 \mathrm{ng} / \mathrm{mL}, p<$ 0.05 ).

Antigen was assayed by ELISA in coded urine samples from 81 healthy control children. A positive test was obtained in urines from seven of $19(37 \%)$ of the healthy nasopharyngeal carriers compared with one of $62(2 \%)$ of the children with negative throat cultures for $\mathrm{Hib}$ (odds ratio $=24.6, p=0.0002$ ). All eight positive samples from the healthy children gave $A$ values well above that of the $A$ value of the normal adult urine which served as a negative control. For example, the individual ratios of the $A$ values in the positive specimens to that of the negative control urine ranged from 3.6 to $>10$ (median $=6.2$ ). In contrast, the mean $\pm \mathrm{SD}$ of the corresponding ratios of the 73 test samples considered negative was $1.00 \pm 0.36$. Thus, all eight of the samples considered positive from the healthy children had ratios $>5 \mathrm{SD}$ above that of the mean of the 73 test samples considered negative.

There was overlap between the antigen concentrations in the urine samples from the seven healthy Hib carriers with positive urines and those of the ill patients. However, the geometric mean of the urine antigen concentrations of the seven carriers with positive urines $(1.9 \mathrm{ng} / \mathrm{mL})$ was significantly lower than that of 


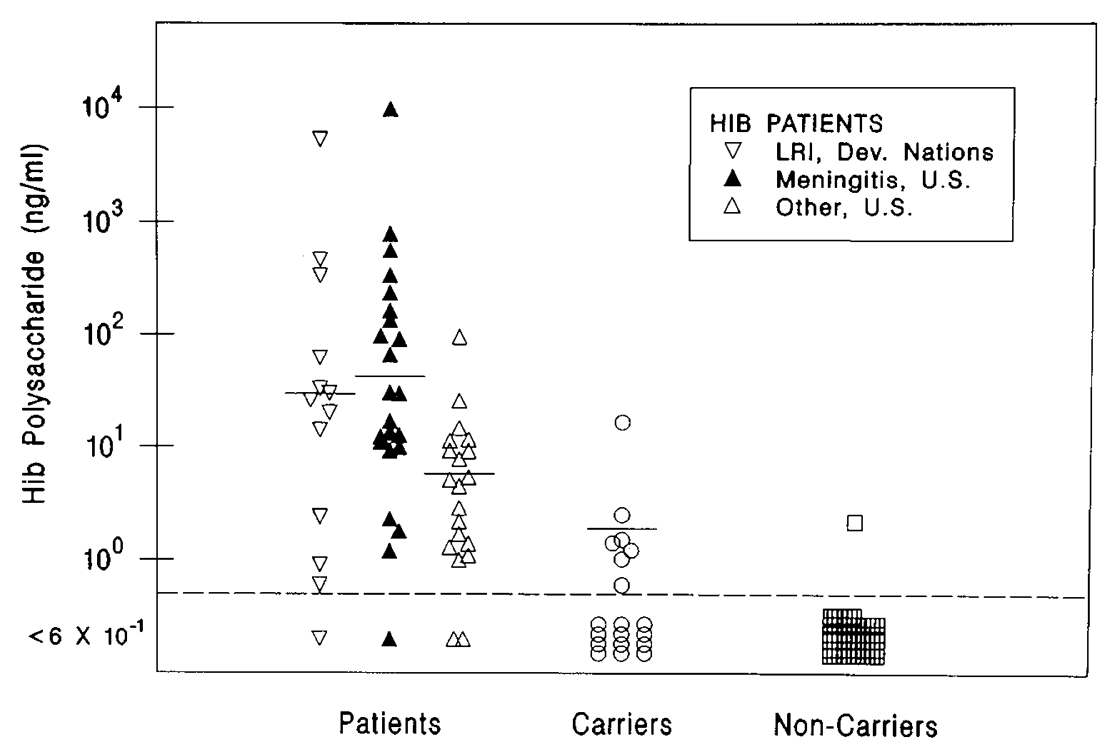

Fig. 2. Concentrations of $H$. influenzae type b polysaccharide measured by ELISA in urine samples from healthy children with positive or negative throat cultures, and from individual patients with culture-proven $H$. influenzae disease (meningitis, other invasive infections not involving the CNS, and lower respiratory infections in patients from developing countries). The horizontal bars represent the respective geometric mean $\mathrm{Ag}$ concentrations of the different groups, and the dashed line represents the lower limit of $\mathrm{Ag}$ detection.

the positive patients with LRI from developing countries $(29.6$ $\mathrm{ng} / \mathrm{mL}, p<0.04)$, or that of the positive patients with meningitis from the United States $(42.5 \mathrm{ng} / \mathrm{mL}, p<0.001)$. The geometric mean urine antigen concentration of the carriers also was lower than that of the urine-positive United States patients with Hib infections not involving the CNS but the difference was not significant $(5.2 \mathrm{ng} / \mathrm{mL}, p=0.08)$.

The urine samples from the healthy carriers also were tested for the presence of Hib PS antigen using two of the commercial particle agglutination tests, Bactigen and Wellcogen. The Bactigen test gave $4^{+}$and $3^{+}$reactions in urines from two of the 19 carriers $(11 \%)$. The two positive samples were those with the greatest concentrations of antigen as determined by ELISA (16.7 and $2.6 \mathrm{ng} / \mathrm{mL}$ ). The Wellcogen test gave a positive reaction in one of the 19 samples (the urine with $16.7 \mathrm{ng} / \mathrm{mL}$ of antigen).

The one child with a negative throat culture for Hib and a positive urine by ELISA had $2.2 \mathrm{ng} / \mathrm{mL}$ of antigen detected. This infant was 5 mo of age and had been afebrile for more than 30 $\mathrm{d}$ before the collection of the urine and throat culture specimens. Of note, this patient's urine was also positive for Hib PS antigen by the Bactigen and Wellcogen agglutination tests $\left(1^{+}\right.$to $2^{+}$, and $1^{+}$, respectively).

\section{DISCUSSION}

The ELISA used in our study was highly sensitive for detection of Hib PS. In general, this assay also was quite specific but, as shown in Figure 1, the assay could detect some other polysaccharides, such as $E$. coli $\mathrm{K} 100$, which is chemically similar and known to cross-react with Hib PS. Therefore, although approximately one-third of the pharyngeal carriers of Hib studied had detectable antigenuria, we can not rigorously prove that the antigen present in their urine was Hib PS. However, this possibility seems compelling given that all but one of the healthy children with antigenuria had positive throat cultures for type $b$ Haemophilus, and the fact that several of the carriers also had antigen detected in their urine by commercial Hib agglutination tests.

False-positive tests for $\mathrm{Hib}$ antigen can be caused by a number of factors, including specimen contamination or actual infection with cross-reacting bacteria $(17,18)$. In our study, urine cultures were not obtained, so we cannot rule out the possibility that the antigenuria in some of the children may have been the result of specimen contamination by cross-reacting bacteria such as $E$. coli $\mathrm{K} 100$ (Fig. 1). However, we consider this possibility unlikely since only one of 62 control children with negative throat cultures for Hib had antigen detected in urine.

During Hib bacteremic infection, type b polysaccharide can be detected in the circulation and in the urine. In previous studies, the presence of $\mathrm{Hib}$ antigen in the urine of ill patients has been considered presumptive evidence of invasive Hib infection $(19,20)$. An exception is children recently vaccinated with Hib polysaccharide in whom Hib polysaccharide can be excreted in the urine for periods of 1 to 10 days (21). Our finding of antigenuria in some carriers suggests that $\mathrm{Hib}$ colonization without clinical evidence of invasive infection also is sufficient to produce antigenuria. The mechanism is unclear. It is possible that some carriers experience transient $\mathrm{Hib}$ bacteremia. Alternatively, antigenuria could result from local bacterial invasion of the mucosal tissues and release of antigen into the circulation. Less likely is the possibility that Hib polysaccharide is swallowed and absorbed directly from the gastrointestinal tract, eventually reaching the circulation and urine.

Previously, we have shown that most Hib carriers $>2$ y of age develop high concentrations of serum anticapsular antibody $(7$, 9). Inasmuch as the children in these studies were generally asymptomatic, we considered it likely that the serum antibody response to Hib colonization was a result of mucosal immunization, i.e. local antigenic stimulation of lymphocytes residing in the nasopharynx with subsequent clonal expansion and trafficking of plasma cells into the circulation and secretion of serum antibody. However, our finding of antigenuria in some children colonized with $\mathrm{Hib}$ suggests that systemic immunization from circulating capsular antigen might be important and possibly necessary for the development of serum anticapsular antibodies in healthy carriers. In their studies of infant rats colonized with Hib, Gilsdorf and Ferrieri (22) reached similar conclusions. They found that colonization alone was insufficient to evoke serum bactericidal activity against $\mathrm{Hib}$, and that bacteremia appeared to be necessary (22). Note, however, that infant rats infected with Hib show low serum anticapsular antibody responses, and the bactericidal antibodies that develop appear to be directed against noncapsular antigens (23).

In summary, our data indicate that a high proportion of asymptomatic children who are carriers of Hib have detectable antigenuria. Questions that remain to be studied include the 
relationship between time of acquisition of carriage and appearance of antigen in the urine, details of the pathophysiology, and the relative roles of mucosal antigenic stimulation versus systemic antigenemia in eliciting serum anticapsular antibody responses in Hib carriers.

Acknowledgments. Francinne Medley, Sharon Coury, Suzanne Cole, and Janet Cromien provided technical assistance. We are grateful to the following investigators for providing urine samples from their patients: Drs. Mercedes Weissenbacher, Buenos Aires, Argentina; Isabella Borrero, Cali, Colombia; Jose Cruz, Guatemala, Guatemala; Deborah Lehmann, Goroka, Papua New Guinea; and Maria Hortal de Peluffo, Montevideo, Uruguay.

\section{REFERENCES}

1. Peltola H, Käyhty H, Virtanen M, Mäkelä PH 1984 Prevention of Haemophilus influenzae type $\mathrm{b}$ bacteremic infections with the capsular polysaccharide vaccine. N Engl J Med 310:1561-1566

2. Robbins JB, Parke JC Jr, Schneerson R, Whisnant JK 1973 Quantitative measurement of "natural" and immunization-induced Haemophilus influenzae type b capsular polysaccharide antibodies. Pediatr Res 7:103-110

3. Schneerson R, Robbins JB 1975 Induction of serum Haemophilus influenzae type b capsular antibodies in adult volunteers fed cross-reacting Escherichia coli O75:K100:H5. N Engl J Med 292:1093-1096

4. Insel RA, Anderson PW 1982 Cross-reactivity with Escherichia coli $\mathrm{K} 100$ in the human serum anticapsular antibody response to Haemophilus influenzae type b. J Immunol 128:1267-1270

5. Sell SH, Turner DJ, Federspiel CF 1973 Natural infections with Haemophilus influenzae in children: I. Types identified. In: Haemophilus influenzae. Sell SHW, Karzon DT (eds). Vanderbilt University Press, Nashville, pp 3-12

6. Michaels RH, Norden CW 1977 Pharyngeal colonization with Haemophilus influenzae type b: a longitudinal study of families with a child with meningitis or epiglottitis due to $H$. influenzae type b. J Infect Dis 136:222-228

7. Granoff DM, Gilsdorf J, Gessert CE, Lowe L 1980 Haemophilus influenzae type $b$ in a day care center: relationship of nasopharyngeal carriage to development of anticapsular antibody. Pediatrics 65:65-68

8. Greenfield S, Peter G, Howie VM, Ploussard JH, Smith DH 1972 Acquisition of type-specific antibodies to Haemophilus influenzae type b. J Pediatr 80:204-208
9. Glode MP, Daum RS, Boies EG, Ballard TL, Murray M, Granoff DM 1985 Effect of rifampin chemoprophylaxis on carriage eradication and new acquisition of Haemophilus influenzae type b in contacts. Pediatrics 76:537542

10. Turk DC, Green CA 1964 Measurement of antibodies reacting with capsular antigens of Haemophilus influenzae. J Clin Pathol 17:294-296

11. Himmelreich CA, Barenkamp SJ, Storch GA 1985 Comparison of methods for serotyping isolates of Haemophilus influenzae. J Clin Microbiol 21:158160

12. Michaels RH, Stonebraker FE, Robbins JB 1975 Use of antiserum agar for detection of Haemophilus influenzae type $b$ in the pharynx. Pediatr Res 9:513-516

13. Barenkamp SJ, Granoff DM, Munson RS Jr 1981 Outer-membrane protein subtypes of Haemophilus influenzae type b and spread of disease in day care centers. J Infect Dis 144:210-217

14. Granoff DM, Shackelford PG, Pandey JP, Boies EG 1986 Antibody responses of Haemophilus influenzae type bolysaccharide vaccine in relation to the $\mathrm{Km}(1)$ and $\mathrm{G} 2 \mathrm{~m}(23)$ immunoglobulin allotypes. J Infect Dis 154:257-264

15. Shenep JL, Munson RS Jr, Barenkamp SJ, Granoff DM 1983 Further studies of the role of noncapsular antibody in protection against experimental Haemophilus influenzae type b bacteremia. Infect Immun 42:257-263

16. Pepple J, Moxon ER, Yolken RH 1980 Indirect enzyme-linked immunosorbent assay for the quantitation of the type-specific antigen of Haemophilus influenzae b: a preliminary report. J Pediatr 97:233-237

17. Schneerson R, Bradshaw MW, Whisnant JK, Myerowitz RL, Parke JC Jr, Robbins JB 1972 An Escherichia coli antigen cross-reactive with the capsular polysaccharide of Haemophilus influenzae type b: occurrence among known serotypes and immunochemical and biological properties of $E$. coli antisera toward $H$. influenzae type b. J Immunol 108:1551-1562

18. Ribner B, Keusch GT, Robbins JB 1975 Staphylococcus aureus antigen in cerebrospinal fluid cross-reactive with Haemophilus influenzae type b antiserum. Ann Intern Med 83:370-371

19. Daum RS, Siber GR, Kamon JS, Russell RR 1982 Evaluation of a commercial latex particle agglutination test for rapid diagnosis of Haemophilus influenzae type $b$ infection. Pediatrics 69:466-471

20. Russell R, Mather F, Siber G, Daum R 1984 Value of antigen quantitation in Haemophilus influenzae type b meningitis. J Pediatr 104:23-28

21. Spinola SM, Sheaffer CI, Philbrick KB, Gilligan PH 1986 Antigenuria after Haemophilus influenzae type b polysaccharide immunization: a prospective study. J Pediatr 109:835-838

22. Gilsdorf JR, Ferrieri P 1985 Role of nasopharyngeal colonization with and without bacteremia in the protection of infant rats against Haemophilus influenzae type b challenge. Infect Immun 47:648-653

23. Granoff D, Rockwell R 1978 Experimental Haemophilus influenzae type b meningitis: immunological investigation of the infant rat model. Infect Immun 20:705-713 